\title{
PERBANDINGAN ANTENA MIKROSTRIP ARRAY DUAL BAND DENGAN PENCATUAN MICROSTRIP LINE DAN ELECTROMAGNETICALLY COUPLED (EMC)
}

\author{
Citra Andrieyani ${ }^{1}$, Bambang Sumajudin ${ }^{2}$, Trasma Yunita ${ }^{3}$ \\ 1, 2, 3 Fakultas Teknik Elektro, Universitas Telkom, Bandung, Indonesia, 40257 \\ ${ }^{1}$ Citraandrieyani@student.telkomuniversity.ac.id, \\ ${ }^{2}$ sumajudin@telkomuniversity.ac.id, ${ }^{3}$ trasmayunita@telkomuniversity.ac.id
}

\begin{abstract}
Abstrak
Antena mikrostrip tunggal memiliki karakteristik bandwidth yang sempit dan gain yang kecil. Pada paper ini membahas perancangan antena mikrostrip array yang bekerja pada dua frekuensi kerja yaitu $2,4 \mathrm{GHz}$ dan $5 \mathrm{GHz}$ untuk WiFi. Metode yang digunakan untuk mendapatkan frekuensi dual band adalah dengan penambahan slot pada sisi patch. Hasil yang didapatkan adalah antena mikrostrip array 4 elemen dengan catuan feed line memiliki hasil yang lebih baik jika diaplikasikan pada WiFi. Antena dengan catuan feed line ini memiliki bandwidth sebesar $75 \mathrm{MHz}$ 184,4 MHz sesuai dengan standar IEEE 802.11n dan memiliki gain sebesar 4,321 dBi. Sedangkan pada catuan EMC, memiliki gain yang besar yaitu sebesar 11,54 dBi namun bandwidth yang didapatkan sangat sempit yaitu sebesar 27,5 MHz.
\end{abstract}

Kata Kunci: Antena array, antena mikrostrip, Dual-Band, EMC, microstrip line.

\section{Abstract}

Single microstrip antenna has the characteristics of narrow bandwidth and small gain. This paper discusses the design of a microstrip array antenna that works at two working frequencies, namely $2.4 \mathrm{GHz}$ and $5 \mathrm{GHz}$ for WiFi. The method used to obtain dual band frequencies is by adding slots on the side of the patch. The results obtained are the 4-element microstrip array antenna with feed line supply has better results when applied to WiFi. This feed line antenna has a bandwidth of $75 \mathrm{MHz}$ - 184.4 MHz in accordance with IEEE 802.11n standards and has a gain of $4.321 \mathrm{dBi}$. Whereas the EMC supply has a large gain of $11.54 \mathrm{dBi}$ but the bandwidth obtained is very narrow, namely $27.5 \mathrm{MHz}$.

Key Words: Array antenna, microstrip antenna, Dual-Band, EMC, microstrip line.

\section{PENDAHULUAN}

Saat ini, antena multi band sudah banyak digunakan dengan alasan lebih praktis dan dapat meminimalisasi space yang digunakan pada sebuah sistem. Antena dual band atau dual frequency merupakan sebuah alternatif yang bisa digunakan pada sistem wireless yang bekerja pada dua kanal frekuensi yang memiliki perbedaan yang cukup jauh. Dual Band Coupling and Feed Structure for Microstrip Filter Design [1], mendesain antena dual frequency yang akan memberikan koneksi jaringan yang lebih baik.

Teknik pencatuan microstrip line saat ini sedang populer karena kemudahan dalam desain dan fabrikasi, karena feed line dan elemen peradiasi dicetak pada subtrat yang sama. Teknik catuan Electromagnetically Coupled (EMC) merupakan teknik catuan tidak langsung. Untuk konfigurasinya, teknik pencatuan
EMC ini menggunakan dua lapisan substrat. Pada bagian atau lapisan atas, terdapat elemen peradiasi antena dan saluran pencatu terletak diantara dua subtrat dielektrik.

Pada penelitian sebelumnya, sudah dilakukan penelitian menggunakan antena MIMO 4x4 untuk teknologi WiFi dengan frekuensi 5,2 GHz [2]. Hasil dari penelitian tersebut menghasilkan nilai bandwidth $60 \mathrm{MHz}$ sampai $90 \mathrm{MHz}$. Dan juga telah ada penelitian MIMO 2x2 untuk teknologi WiFi dengan catuan Electromagnetically Coupled (EMC) dengan frekuensi 5,2 GHz. Dan hasil yang didapat pada Tugas Akhir tersebut memiliki nilai bandwidth $141 \mathrm{MHz}$ [3]. Pada paper akhir ini akan dirancang antena Mikrostrip Array patch rectangular untuk Dual-Band dengan frekuensi 2,4 GHz dan $5 \mathrm{GHz}$ dan akan membandingkan hasil teknik catuan mikrostrip line dengan catuan EMC. 


\section{KONSEP DASAR}

Antena mikrostrip adalah suatu konduktor yang menempel diatas ground plane yang dilapisi bahan dielektrik. Antena mikrostrip merupakan sebuah antena yang tersusun atas 4 elemen, yaitu elemen peradiasi (patch), substrat, saluran pencatu (feed line) dan bidang pentahanan (ground plane) seperti yang terlihat pada Gambar 1.

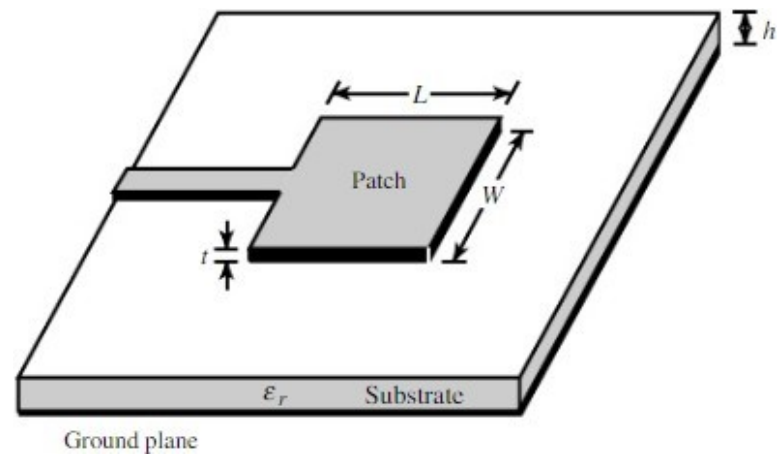

Gambar 1. Susunan Antena Mikrostrip

\subsection{Antena Patch Rectangular}

Bentuk patch antena mikrostrip sangat beragam, salah satunya adalah antena patch rectangular. Antena patch rectangular merupakan bentuk patch yang paling sering digunakan karena kemudahan dalam analisis, dan mudah di fabrikasi.

Untuk merancang antena mikrostrip patch segi empat, terlebih dahulu harus mengetahui parameter bahan yang akan digunakan, seperti konstanta dielektrik $\left(\varepsilon_{r}\right)$, dan ketebalan dielektrik $(h)$. Dari nilai tersebut ukuran patch berbentuk segi empat berupa lebar $(W)$ dan panjang $(L)$ dapat diperoleh dari persamaan berikut [4]:

$$
W=\frac{c}{2 f r \sqrt{\frac{\varepsilon_{r}+1}{2}}}
$$

Dimana $W$ adalah lebar konduktor, $c$ merupakan kecepatan cahaya diruang bebas (3x108), $f r$ merupakan frekuensi kerja antena. Sedangkan untuk menghitung panjang patch $(L)$ memerukan parameter $\Delta L$ yang merupakan pertambahan panjang $L$ akibat fringing effect. Untuk menghitung $\Delta L$ dapat dicari dengan menggunakan persamaan:

$$
\Delta L=0.421 h \frac{\left(\varepsilon_{r e f f}+0.3\right)+\left(\frac{W p}{h}+0.264\right)}{\left(\varepsilon_{r e f f}-0.258\right)\left(\frac{W p}{h}+0.8\right)}
$$

Dimana $h$ merupakan ketebalan substrat, $\varepsilon_{\text {reff }}$ merupakan konstanta dielektrik yang diperoleh dengan persamaan:

$$
\varepsilon_{r e f f}=\frac{\varepsilon_{r}+1}{2}+\frac{\varepsilon_{r}-1}{2}\left[\frac{1}{\sqrt{1+\frac{12 h}{w}}}\right]
$$

Maka panjang patch dapat dihitung menggunakan persamaan:

$$
L=\frac{c}{2 f_{r} \sqrt{\varepsilon_{r e f f}}}-2 \Delta L
$$

Untuk memperoleh dimensi ground plane dapat menggunakan persamaan:

$$
\begin{aligned}
W_{g} & =6 h+W_{\text {patch }} \\
L_{g} & =6 h+L_{\text {patch }}
\end{aligned}
$$

\subsection{Antena Array}

Antena array adalah susunan dari beberapa antena yang identik dengan susunan yang teratur. Sinyal dari beberapa antena tersebut digabungkan untuk dapat meningkatkan performansi sebuah antena. Antena array bertujuan untuk meningkatkan nilai gain pada antena, meningkatkan nilai keterarahan (direktivitas) antena, dan penentu arah kedatangan sinyal.

Terdapat beberapa macam konfigurasi antena array, salah satu konfigurasi antena array adalah antena array linear, dimana konfigurasi ini meletakkan antena pada satu garis lurus. Pada Gambar 2. Adapun

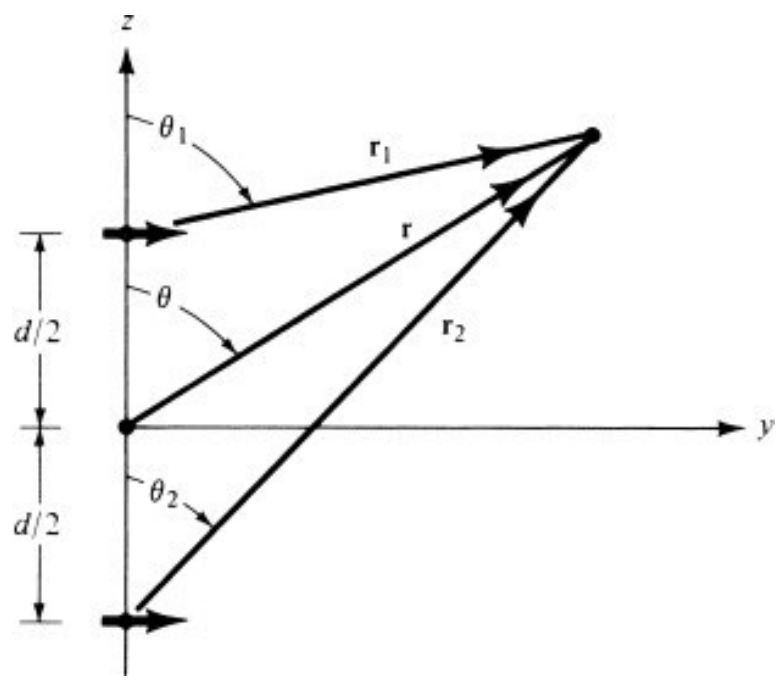

Gambar 2. Array Linear

rumus yang bisa digunakan untuk merancang antena array adalah [4]:

$$
\begin{aligned}
d & =\frac{\lambda}{2} \\
A F & =2 \cos \left[\frac{1}{2}(k d \cos \theta+\beta)\right]
\end{aligned}
$$


Dimana, $d$ merupakan jarak antar elemen patch dan $A F$ merupakan faktor pengali dari medan elektrik dari antena single element, $k$ merupakan konstanta pergeseran fasa sebesar $\frac{2 \pi}{\lambda}$ dan $\theta$ adalah sudut main beam antena array, $\beta$ adalah beda fasa catuan setiap elemen array.

Penyesuaian impedansi dilakukan agar terpenuhi nilai $Z_{0}=Z_{L}$, dimana $Z_{0}$ merupakan karakteristik impedansi suatu saluran transmisi yang umumnya bernilai $50 \mathrm{ohm}$, sedangkan $Z_{L}$ merupakan impedansi beban, dengan kata lain tidak ada refleksi yang terjadi pada ujung saluran beban [5]. Saluran transmisi mempunyai fungsi utama yaitu untuk mentransfer daya dengan sempurna, maka beban yang match sangat dibutuhkan. Untuk itu, dibutuhkan suatu cara agar bisa mendapatkan kondisi matching, yaitu salah satu cara nya adalah menambahkan transformator $\frac{\lambda}{4}$. Desain transformator $\frac{\lambda}{4}$ dapat dilihat pada Gambar 3 .

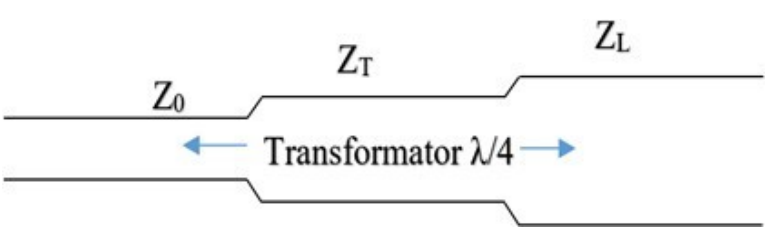

Gambar 3. Desain transformator $\frac{\lambda}{4}$

\subsection{Teknik Catuan Microstrip Line}

Teknik catuan pada antena mikrostrip merupakan suatu teknik untuk mentransmisikan energi elekromagnetik ke antena mikrostrip. Teknik pencatuan Microstrip line saat ini sedang populer karena kemudahan dalam desain dan fabrikasi, karena feed line dan elemen peradiasi dicetak pada subtrat yang sama. Pada teknik pencatuan microstrip line ini, untuk me-matching-kan antena, patch antena dihubungkan dengan saluran pencatu dimana patch dan saluran pencatu harus menggunakan bahan yang sama dengan cara di matching-kan, seperti yang terlihat pada Gambar 4.

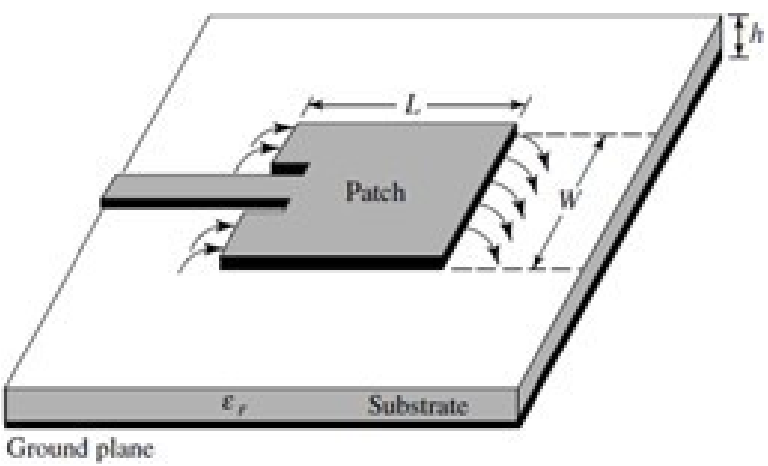

Gambar 4. Teknik catuan microstrip line

\subsection{Teknik Catuan EMC}

Teknik pencatuan dengan menggunakan kopling elektromagnetik merupakan teknik pencatuan yang berbeda dan yang paling menguntungkan dibanding teknik pencatuan lainnya, karena pada teknik ini kemunculan radiasi yang mengganggu sangat kecil dan akan menghasilkan bandwidth yang lebih lebar.

Teknik pencatuan EMC ini menggunakan dua lapisan substrat. Pada bagian atau lapisan atas, terdapat elemen peradiasi antena dan saluran pencatu terletak diantara dua subtrat dielektrik seperti yang terlihat pada Gambar 5. Substrat dielektrik yang digunakan pada teknik ini bisa menggunakan substrat dielektrik yang berbeda dimana masing-masing satu untuk saluran pencatu dan satu substrat untuk elemen peradiasi antena. Geometri antena mikrostrip menggunakan saluran mikrostrip yang dikopel secara proximity [6].

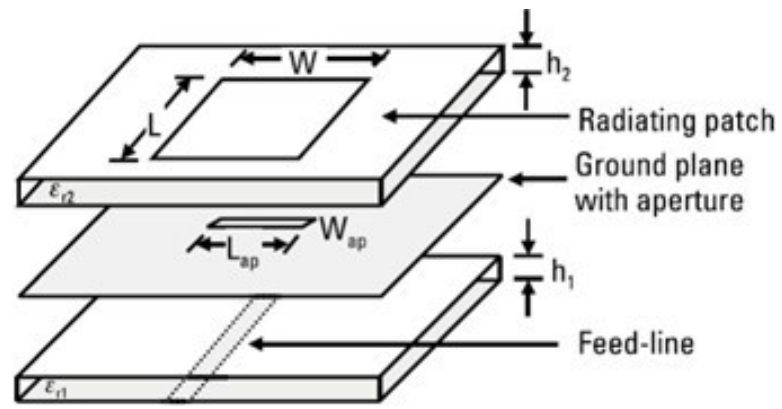

\section{Gambar 5. Teknk catuan Electromagnetically Coupled}

\subsection{Antena Dual Band}

Untuk menghasilkan antena mikrostrip dual band atau dual frekuensi terdapat tiga jenis bentuk patch yaitu, orthogonal- mode dual-frequency patch antenna, multi-patch dual- frequency antenna, dan reactively-loaded dual-frequency patch antenna [7]. Pada penelitian kali ini akan digunakan patch jenis reactively-loaded dual-frequency patch antenna dengan menggunakan teknik penambahan slot. Slot yang dirancang pada patch antena ini adalah penambahan slot rectangular.

\section{MODEL SISTEM DAN PERANCANGAN}

Sebelum melakukan perancangan antena, langkah awal yaitu menetukan spesifikasi dan bentuk antena yang akan dirancang terlebih dahulu.

\subsection{Spesifikasi Antena}

Sebelum melakukan perancangan, terlebih dahulu menentukan spesifikasi antena yang diinginkan. Adapun spesifikasi yang diinginkan seperti yang terlihat pada Tabel 1. 
Tabel 1. Spesifikasi antena

\begin{tabular}{|c|c|}
\hline Frekuensi Kerja & $2,4 \mathrm{dan} 5 \mathrm{GHz}$ \\
\hline Bandwidth & $50 \mathrm{MHz}$ \\
\hline Pola Radiasi & Directional \\
\hline Polarisasi & Linear \\
\hline Gain & $3 \mathrm{~s} / \mathrm{d} 4 \mathrm{dBi}$ \\
\hline VSWR & $<1.8$ \\
\hline
\end{tabular}

\subsection{Pemilihan Bahan Antena}

Bahan yang digunakan adalah Epoxy FR4 yang mempunyai permitivitas relatif $\left(\varepsilon_{r}\right)=4,4$ dengan ketebalan substrat $(h)=1,6 \mathrm{~mm}$. Pemilihan bahan substrat jenis ini karena memiliki dimensi antena yang kecil, dimana semakin kecil dimensi antena maka akan semakin mudah untuk difabrikasi.

\subsection{Dimensi Antena}

Sebelum menghitung dimensi antena, hal yang dilakukan terlebih dahulu adalah menghitung nilai paramater-parameter yang sudah ditentukan dengan dimasukkan kedalam persamaan untuk mendapat nilai dimensi yang diinginkan tersebut. Perlu diketahui, frekuensi kerja serta jenis dan ketebalan bahan substrat dapat berpengaruh untuk dimensi antena yang digunakan. Perhitungan dilakukan dengan persamaan (1) sampai dengan persamaan (6).

Lebar patch dihitung dari persamaan (1), maka nilai $W_{p}$ untuk frekuensi $2,4 \mathrm{GHz}=36,515 \mathrm{~mm}$ dan untuk frekuensi $5 \mathrm{GHz}=17,555 \mathrm{~mm}$. Menghitung $\varepsilon_{\text {reff }}$ dengan menggunakan persamaan (3), maka nilai $\varepsilon_{\text {reff }}$ untuk frekuensi $2,4 \mathrm{GHz}=4,076 \mathrm{~mm}$ dan $\varepsilon_{\text {reff }}$ untuk frekuensi $5 \mathrm{GHz}=3,875 \mathrm{~mm}$. Menghitung $\Delta L$ dengan menggunakan persamaan (2), maka nilai $\Delta L$ untuk frekuensi $2,4 \mathrm{GHz}=0,738 \mathrm{~mm}$ dan $\Delta L$ untuk frekuensi $5 \mathrm{GHz}=0,726 \mathrm{~mm}$. Menghitung $L_{p}$ dengan menggunakan persamaan (4), maka nilai $L_{p}$ untuk frekuensi $2,4 \mathrm{GHz}=28,241 \mathrm{~mm}$ dan $L_{p}$ untuk frekuensi $5 \mathrm{GHz}=13,202 \mathrm{~mm}$. Panjang Ground Plane dihitung dengan persamaan (6), maka nilai $L_{g}$ untuk frekuensi $2,4 \mathrm{GHz}=44,241 \mathrm{~mm}$. Sedangkan untuk menghitung Lebar Ground Plane dengan persamaan (5), maka nilai $W_{g}$ untuk frekuensi $2,4 \mathrm{GHz}=52,515$ $\mathrm{mm}$.

\subsection{Simulasi Antena Single Catuan Feed Line}

Pada paper ini, dilakukan perancangan antena single patch terlebih dahulu sebelum merancang antena array. Antena single patch tersebut dilakukan optimasi terlebih dahulu agar sesuai dengan spesifikasi yang diharapkan. Apabila antena single patch belum sesuai spesifikasi, maka akan dilakukan optimasi dengan cara mengubah nilai parameter-parameter antena. Jika antena single patch telah sesuai spesifikasi, maka tahap selanjutnya adalah penyusunan antena array.

Pada tahap ini, dirancang antena single dengan catuan feed line berdasarkan parameter-parameter yang telah dihitung. Setelah dirancang antena berdasarkan perhitungan, hasil yang didapatkan masih jauh dari spesifikasi yang diinginkan, maka dilakukan optimasi agar mendapatkan hasil yang diinginkan. Pada Tabel 2 menunjukkan dimensi antena single elemen menggunakan catuan feed line sesudah optimasi.

\section{Tabel 2. Dimensi single elemen dengan catuan feed} line

\begin{tabular}{|c|c|c|c|}
\hline No & Parameter & $\begin{array}{c}\text { Nilai sesuai } \\
\text { perhitungan }\end{array}$ & $\begin{array}{c}\text { Nilai setelah } \\
\text { optimasi }\end{array}$ \\
\hline 1 & $\mathrm{Lg}$ & $44,241 \mathrm{~mm}$ & $97,1 \mathrm{~mm}$ \\
\hline 2 & $W g$ & $52,515 \mathrm{~mm}$ & $73,3 \mathrm{~mm}$ \\
\hline 3 & Lf & $14,859 \mathrm{~mm}$ & $25 \mathrm{~mm}$ \\
\hline 4 & Wf & $3,058 \mathrm{~mm}$ & $5.5 \mathrm{~mm}$ \\
\hline 5 & Lp & $28,241 \mathrm{~mm}$ & $54,2 \mathrm{~mm}$ \\
\hline 6 & Wp & $36,515 \mathrm{~mm}$ & $66,6 \mathrm{~mm}$ \\
\hline 7 & Ls & $13,202 \mathrm{~mm}$ & $26 \mathrm{~mm}$ \\
\hline 8 & Ws & $17,555 \mathrm{~mm}$ & $40 \mathrm{~mm}$ \\
\hline
\end{tabular}

Setelah dilakukan optimasi sesuai dengan yang tertera pada Tabel 2, maka didapatkan hasil dari parameter-parameter antena seperti berikut:

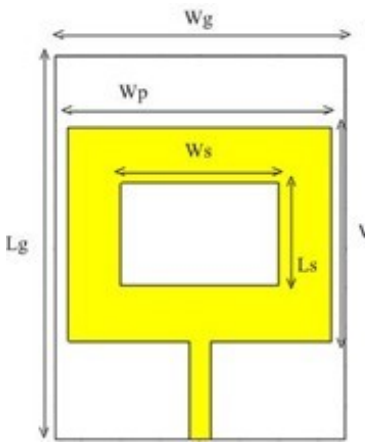

(a)

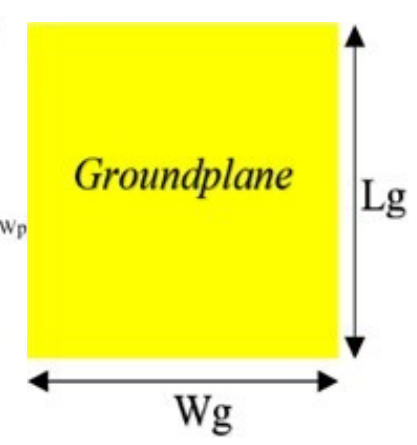

(b)
Gambar 6. Desain antena single. (a) Tampak depan, (b) Tampak belakang

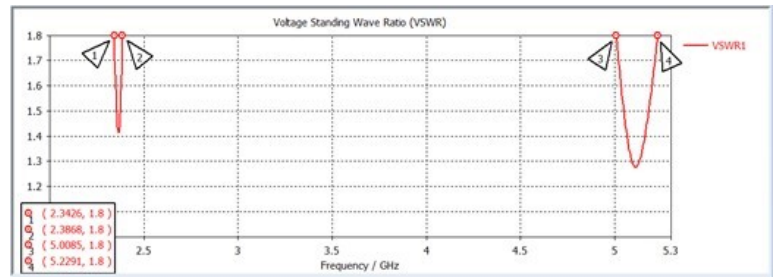

Gambar 7. VSWR antena single

Pada Gambar 7 terlihat antena telah bekerja di 
frekuensi dual band. Namun, pada frekuensi 2,4 belum mencapai VSWR $\leq 1.8$, yaitu masih di 2.2871. Sedangkan pada frekuensi $5 \mathrm{GHz}$, VSWR telah memenuhi spesifikasi yaitu dengan nilai VSWR 1,8746. Maka akan dilakukan optimasi kembali agar frekuensi bekerja sesuai spesifikasi yang ditentukan. Untuk bandwidth, seperti yang terlihat pada Gambar 7, bahwa antena memiliki bandwidth sebesar $56,4 \mathrm{MHz}$ dan pada frekuensi $5 \mathrm{GHz}$ memiliki bandwidth sebesar 271,8 MHz dan telah sesuai dengan spesifikasi yang diinginkan. Dan untuk nilai gain, pada antena single catuan feed line ini memiliki gain yang kecil, yaitu $-0,6370 \mathrm{~dB}$ pada frekuensi 2,3646 $\mathrm{GHz}$, sedangkan pada frekuensi $5 \mathrm{GHz}$ memiliki nilai gain 3,049 dB.

Setelah didapatkan hasil yang diinginkan, maka selanjutnya adalah merancang antena array mikrostrip 4 elemen berdasarkan antena single patch yang telah dioptimasi selanjutnya. Di harapkan dari merancang antena array ini dapat meningkatkan nilai gain yang masih jauh dari spesifikasi yang diinginkan.

\subsection{Simulasi Antena Array 4 Elemen Catuan Feed Line}

Sebelum melakukan perancangan antena, dilakukan perhitungan jarak antar patch yang dipisahkan sejauh $\frac{\lambda}{2}$. Dimensi antena single yang telah dioptimasi, akan digunakan sebagai acuan untuk perancangan antena array 4 elemen. Antena array ini akan disusun secara linear. Perancangan antena array ini diharapkan akan memiliki nilai gain yang meningkat dibandingkan dengan desain antena single. Dalam perancangan antena array 4 elemen, akan digunakan 3 buah saluran pencatu yaitu $50 \Omega, 70.7 \Omega$ dan $100 \Omega$. T-Junction itu sendiri berfungsi sebagai pembagi daya atau power divider.

Dimensi awal antena array ini berdasarkan dari antena single catuan feed line yang telah dioptimasi. Namun saat merancang antena array menggunakan dimensi antena single patch yang telah dioptimasi, hasil yang diperoleh masih jauh dari spesifikasi yang diinginkan, maka akan dilakukan optimasi agar mendapatkan hasil yang sesuai spesifikasi. Pada Tabel 3 merupakan dimensi antena array dengan catuan feed line setelah optimasi.

Setelah dilakukan optimasi seperti yang tertera pada Tabel 3, maka didapatkan hasil parameter-parameter antena sebagai berikut:

Pada Gambar 9 menunjukkan bahwa antena telah bekerja pada frekuensi dual band $2.4 \mathrm{GHz}$ dan $5 \mathrm{GHz}$. Pada frekuensi $2.4 \mathrm{GHz}$ antena memiliki VSWR sebesar 1,2177. Nilai VSWR sudah baik karena berada dibawah $\leq 2$. Sedangkan pada frekuensi $5 \mathrm{GHz}$ antena memiliki VSWR sebesar 1.3953. Pada gambar tersebut menunjukkan nilai bandwidth yang didapatkan setelah optimasi. Untuk frekuensi $2.4 \mathrm{GHz}$, nilai bandwidth
Tabel 3. Dimensi antena array catuan feed line

\begin{tabular}{|c|c|c|}
\hline Parameter & Dimensi & Keterangan \\
\hline $\mathrm{Lg}$ & $98,1 \mathrm{~mm}$ & Panjang Groundplane \\
\hline $\mathrm{Wg}$ & $68,3 \mathrm{~mm}$ & Lebar Groundplane \\
\hline $\mathrm{Lp}$ & $50,2 \mathrm{~mm}$ & Panjang Patch \\
\hline $\mathrm{Wp}$ & $66,6 \mathrm{~mm}$ & Lebar Patch \\
\hline $\mathrm{Ls}$ & $27 \mathrm{~mm}$ & Panjang Slot \\
\hline Ws & $35 \mathrm{~mm}$ & Lebar Slot \\
\hline Wf50 & $3,08 \mathrm{~mm}$ & Lebar feed line $50 \Omega$ \\
\hline Lf50 & $8,55 \mathrm{~mm}$ & Panjang feed line $50 \Omega$ \\
\hline Wf70 & $1,64 \mathrm{~mm}$ & Lebar feed line $70 \Omega$ \\
\hline Lf70 & $17,64 \mathrm{~mm}$ & Panjang feed line $70 \Omega$ \\
\hline Wf100 & $0,63 \mathrm{~mm}$ & Lebar feed line $100 \Omega$ \\
\hline $\mathrm{d}$ & $14,3 \mathrm{~mm}$ & Jarak Antar Elemen \\
\hline
\end{tabular}

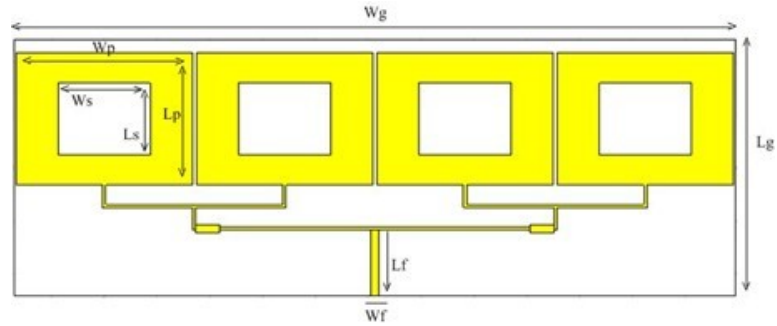

Gambar 8. Desain antena array dengan catuan feed line

mencapai 76,3 MHz, sedangkan pada frekuensi $5 \mathrm{GHz}$, nilai bandwidth sebesar 379,4 MHz. Pada perancangan antena array catuan feed line ini memiliki polarisasi linier karena $\mathrm{AR}=40 \mathrm{~dB}$ pada kedua frekuensi. Untuk pola radiasi, pada perancangan antena array catuan ini memiliki pola radiasi directional atau pola radiasi satu arah. Nilai dari gain antena array yang telah dioptimasi pada frekuensi $2.4 \mathrm{GHz}$ didapatkan nilai gain sebesar $3.056 \mathrm{~dB}$, sedangkan pada frekuensi 5 $\mathrm{GHz}$, didapatkan nilai gain yang meningkat yaitu $4.321 \mathrm{~dB}$. Dapat disimpulkan bahwa desain antena array 4 elemen catuan feed line ini telah memenuhi spesifikasi yang ditentukan, sehingga dimensi desain antena ini yang akan direalisasikan nantinya.

\subsection{Simulasi Antena Array 4 Elemen Catuan EMC}

Setelah perancangan antena array 4 elemen dengan catuan feed line, selanjutnya adalah merancang antena array 4 elemen dengan catuan EMC, agar hasil dari simulasi kedua catuan tersebut dibandingkan dan dilakukan analisis lebih lanjut. Pada perancangan antena array catuan EMC ini menggunakan hasil dimensi yang telah dioptimasi pada antena array catuan feed line agar mendapatkan hasil yang diinginkan dan tidak terlalu banyak melakukan optimasi pada setiap parameternya. Namun, ketika merancang antena array dengan catuan EMC 


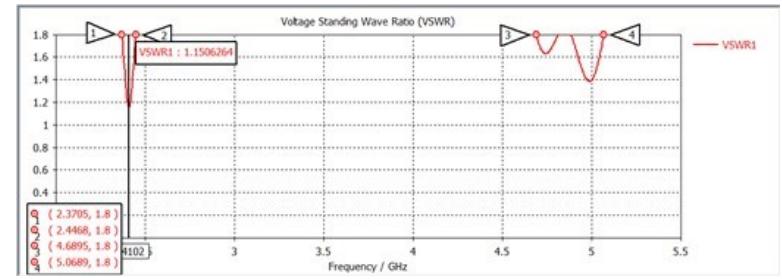

Gambar 9. VSWR antena array dengan catuan feed line

berdasarkan dimensi pada antena array catuan feed line, hasil yang diperoleh masih jauh dari spesifikasi yang diinginkan, maka akan dilakukan optimasi agar mendapatkan spesifikasi yang sesuai. Pada Tabel 4 menunjukkan dimensi antena array dengan catuan EMC sesudah optimasi.

Tabel 4. Dimensi antena array catuan EMC

\begin{tabular}{|c|c|c|}
\hline Parameter & Dimensi & Keterangan \\
\hline $\mathrm{Lg}$ & $117 \mathrm{~mm}$ & Panjang Groundplane \\
\hline $\mathrm{Wg}$ & $68,3 \mathrm{~mm}$ & Lebar Groundplane \\
\hline $\mathrm{Lp}$ & $46,2 \mathrm{~mm}$ & Panjang Patch \\
\hline $\mathrm{Wp}$ & $66,6 \mathrm{~mm}$ & Lebar Patch \\
\hline $\mathrm{Ls}$ & $27 \mathrm{~mm}$ & Panjang Slot \\
\hline $\mathrm{Ws}$ & $30 \mathrm{~mm}$ & Lebar Slot \\
\hline Wf50 & $3,08 \mathrm{~mm}$ & Lebar feed line $50 \Omega$ \\
\hline Lf50 & $8,55 \mathrm{~mm}$ & Panjang feed line $50 \Omega$ \\
\hline Wf70 & $1,64 \mathrm{~mm}$ & Lebar feed line $70 \Omega$ \\
\hline Lf70 & $17,64 \mathrm{~mm}$ & Panjang feed line $70 \Omega$ \\
\hline Wf100 & $0,63 \mathrm{~mm}$ & Lebar feed line $100 \Omega$ \\
\hline $\mathrm{d}$ & $14,3 \mathrm{~mm}$ & Jarak Antar Elemen \\
\hline
\end{tabular}

Setelah dilakukan optimasi seperti yang tertera pada Tabel 3, maka didapatkan hasil parameter-parameter antena sebagai berikut:

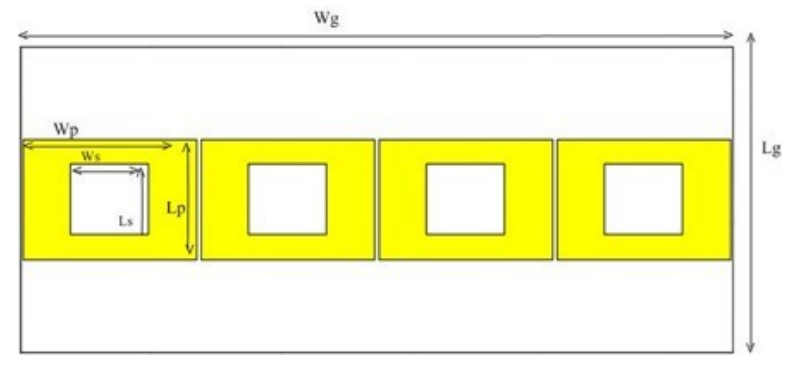

Gambar 10. Desain antena array dengan catuan EMC

Pada Gambar 11 menunjukkan bahwa antena array 4 elemen catuan EMC telah bekerja pada frekuensi dual band $2,4 \mathrm{GHz}$ dan $5 \mathrm{GHz}$. Pada frekuensi 2,4 GHz memiliki nilai VSWR sebesar 1,561 dan pada frekuensi $5 \mathrm{GHz}$ nilai VSWR mencapai

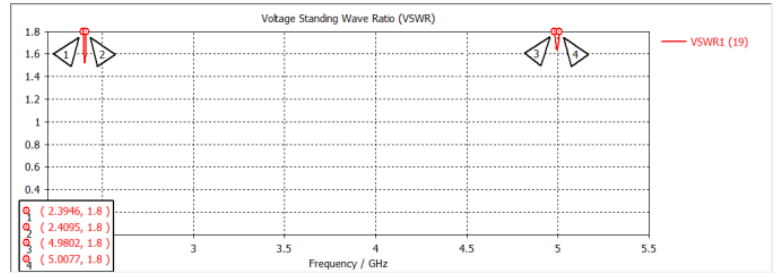

\section{Gambar 11. VSWR antena array dengan catuan} EMC

1,671. Untuk nilai bandwidth juga dapat dilihat pada Gambar 11, pada gambar tersebut terlihat range frekuensi yang didapatkan, yaitu 2,4095 2,3946 GHz maka didapatkan nilai bandwidth sebesar 14,9 $\mathrm{MHz}$. Dan rentang 5,0077 4,9802 GHz memiliki bandwidth 27,5 MHz. Pada perancangan antena array 4 elemen catuan EMC ini memiliki polarisasi linear di kedua frekuensi, sama seperti antena array 4 elemen catuan feed line. Dikatakan linear, karena memiliki AR $=40$ Db. Pola radiasi yang dihasilkan pada perancangan antena ini adalah pola radiasi directional yaitu pola radiasi satu arah.

\section{PERBANDINGAN HASIL DAN REALISASI ANTENA}

Setelah mendapatkan hasil simulasi perancangan antena dengan teknik catuan feed line dan juga dengan teknik catuan EMC, maka tahap selanjutnya adalah melakukan realisasi antena. Antena yang akan direalisasikan pada peneilitian ini adalah antena array 4 elemen dengan catuan feed line, karena hasil simulasi perancangan dengan teknik catuan ini lebih baik dibandingkan dengan teknik catuan EMC jika untuk diaplikasikan pada $\mathrm{WiFi}$.

\subsection{Analisis Pengukuran VSWR}

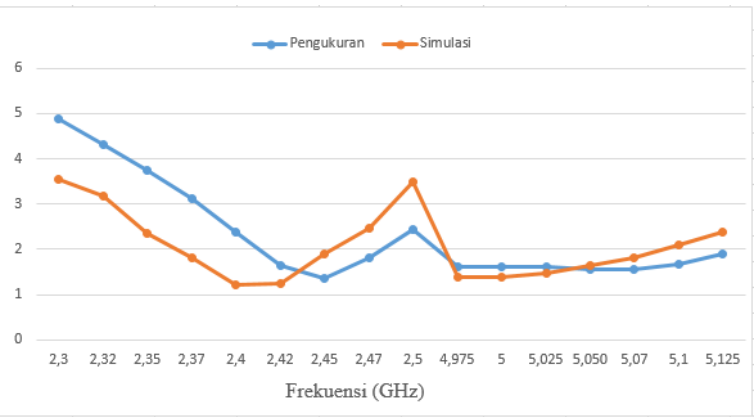

\section{Gambar 12. Perbandingan hasil VSWR simulasi dan pengukuran}

Antena yang telah direalisasikan memiliki nilai VSWR 1,352 pada frekuensi tengah $2,45 \mathrm{GHz}$, sedangkan pada hasil simulasi nilai VSWR sebesar 1,151 dengan frekuensi tengah 2,4086 GHz, 
sedangkan pada frekuensi tengah $5,065 \mathrm{GHz}$ nilai VSWR sebesar 1,556 dan pada simulasi nilai VSWR sebesar 1,766 pada frekuensi $5 \mathrm{GHz}$. Pada Gambar 412 terlihat bahwa nilai VSWR saat pengukuran lebih tinggi daripada hasil simulasi. Namun nilai VSWR masih memenuhi spesifikasi yang diinginkan dan masih bernilai dibawah 2 .

\subsection{Analisis Pengukuran Bandwidth}

Bandwidth adalah rentang frekuensi suatu antena dapat bekerja dengan baik. Untuk pengukuran bandwidth akan ditinjau dari kurva return loss. Pada Tabel 5 merupakan perbandingan hasil bandwidth pengukuran dan hasil simulasi.

Tabel 5. Perbandingan bandwidth hasil pengukuran dan simulasi

\begin{tabular}{|r|c|c|}
\hline \multirow{2}{*}{ Frekuensi $(\mathrm{GHz})$} & \multicolumn{2}{|c|}{ Bandwidth $(\mathrm{MHz})$} \\
\cline { 3 - 4 } & Pengukuran & Simulasi \\
\hline $2,4182,475$ & 57 & 91,5 \\
\hline $4,8595,115$ & 256 & 428,3 \\
\hline
\end{tabular}

Pada penelitian pengukuran parameter dalam terdapat perbedaan antara hasil pengukuran dan hasil simulasi baik untuk nilai VSWR, bandwidth maupun return loss, dapat disebabkan oleh pabrikasi antena yang kurang presisi dikarenakan tingkat kesulitan dalam fabrikasi tersebut dan dibutuhkan tingkat ketelitian yang tinggi.

\subsection{Analisis Pengukuran Gain}

Pada pengukuran gain kali ini menggunakan metode Gain Transfer Method atau Gain Comparison Method. Pengukuran gain ini memerlukan dua buah antena referensi dan satu antenna under test. Antena Referensi adalah Double Ridge Guide Horn Antenna, dan AUT adalah antena array 4 elemen catuan feed line. Pengukuran dipisahkan dengan jarak 2 meter, dengan persamaan rumus gain:

$$
\text { Gain }=P_{a u t}-P_{r e f}+G_{R e f}
$$

Dimana, $P_{\text {aut }}$ merupakan daya terima antenna under test, Pref merupakan daya yang diterima antena standar (DRG Horn), dan Gref merupakan gain antena referensi absolut isotropic.

Tabel 6. Pengukuran nilai gain

\begin{tabular}{|c|c|c|}
\hline Frekuensi $(\mathrm{GH})$ & $\begin{array}{c}\text { Daya Terima } \\
\text { AUT }\end{array}$ & $\begin{array}{c}\text { Daya Terima } \\
\text { Antena referensi }\end{array}$ \\
\hline 2,45 & $-38,02 \mathrm{dBm}$ & $-31,49 \mathrm{dBm}$ \\
\hline 5,062 & $-46,88 \mathrm{dBm}$ & $-37,14 \mathrm{dBm}$ \\
\hline
\end{tabular}

1. Perhitungan nilai gain pada frekuensi $2,45 \mathrm{GHz}$ $G=P_{\text {aut }} P_{\text {ref }}+G_{\text {Ref }}$

$G=(-38,02)(-31,49)+9,2=2,67 d B i$.

2. Perhitungan nilai gain pada frekuensi $5,062 \mathrm{GHz}$ $G=P_{\text {aut }} P_{\text {ref }}+G_{\text {Ref }}$

$G=(-46,88)(-37,14)+8,8=-1,27 d B i$.

\subsection{Perbandingan Catuan Feedline Dan EMC}

Tabel 7. D. Perbandingan Catuan Feed line Dan EMC

\begin{tabular}{|c|c|c|c|c|}
\hline \multirow{2}{*}{ Parameter } & \multicolumn{2}{|c|}{$\begin{array}{c}\text { Antena array catuan } \\
\text { feed line }\end{array}$} & \multicolumn{2}{c|}{$\begin{array}{c}\text { Antena array } \\
\text { catuan EMC }\end{array}$} \\
\cline { 2 - 5 } & $\begin{array}{c}2,408 \\
\mathrm{GHz}\end{array}$ & $\begin{array}{c}5 \\
\mathrm{GHz}\end{array}$ & $\begin{array}{c}2,402 \\
\mathrm{GHz}\end{array}$ & $\begin{array}{c}5 \\
\mathrm{GHz}\end{array}$ \\
\hline VSWR & 1,151 & 1,395 & 1,533 & 1,671 \\
\hline $\begin{array}{c}\text { Bandwidth } \\
(\mathrm{MHz})\end{array}$ & 76,3 & 184,4 & 14,9 & 27,5 \\
\hline $\begin{array}{c}\text { Gain } \\
(\mathrm{dBi})\end{array}$ & 3,056 & 4,321 & 11,54 & 8,897 \\
\hline $\begin{array}{c}\text { Pola } \\
\text { Radiasi }\end{array}$ & $\begin{array}{c}\text { Direc- } \\
\text { tional }\end{array}$ & $\begin{array}{c}\text { Direc- } \\
\text { tional }\end{array}$ & $\begin{array}{c}\text { Direc- } \\
\text { tional }\end{array}$ & $\begin{array}{c}\text { Direc- } \\
\text { tional }\end{array}$ \\
\hline Polarisasi & Linear & Linear & Linear & Linear \\
\hline
\end{tabular}

Pada Tabel 6 memperlihatkan hasil simulasi perancangan antena array 4 elemen dengan dua teknik catuan yang berbeda. Pada catuan feed line memiliki kelebihan pada sisi bandwidth yang lebar hingga mencapai 184,4 MHz, sedangkan pada catuan EMC hanya memiliki bandwidth 14,9 27,5 $\mathrm{MHz}$. Bandwidth pada catuan EMC bisa dikatakan sangat sempit, namun catuan EMC memiliki keunggulan pada sisi nilai gain yang sangat besar yaitu mencapai 11,54 dB. Hasil pola radiasi pada kedua teknik catuan ini memiliki pola radiasi directional yang artinya pola pancar antena ini mencakup ke satu arah. Dapat ditarik kesimpulan, bahwa kedua teknik catuan ini memiliki kekurangan dan keunggulan masing-masing. Jika perancangan antena ingin memiliki nilai gain yang besar, maka bisa menggunakan teknik catuan EMC, namun harus melakukan optimasi kembali agar mendapatkan nilai bandwidth yang lebar. Begitu juga sebaliknya, jika kebutuhan antena ingin mendapatkan bandwidth yang lebar, catuan feed line bisa menjadi solusi.

\section{KESIMPULAN}

Antena array 4 elemen dengan catuan feed line memiliki performansi yang lebih baik dibandingkan dengan catuan EMC jika diaplikasikan pada WiFi karena pada catuan feedline memiliki bandwidth yang cukup lebar yaitu sebesar 184,4 MHz sedangkan pada catuan EMC memiliki bandwidth yang sangat sempit 
yaitu hanya sebesar 27,5 MHz. Walaupun catuan EMC memiliki keunggulan pada nilai gain yang cukup besar yaitu sebesar 11,54 dBI namun nilai gain pada catuan feed line juga telah memenuhi spesifikasi yang ditentukan yaitu sebesar 4,321 dBI.

\section{Daftar Pustaka}

[1] H.-M. Lee, C.-R. Chen, C.-C. Tsai, and C.-M. Tsai, "Dual-band coupling and feed structure for microstrip filter design," in 2004 IEEE MTT-S International Microwave Symposium Digest (IEEE Cat. No. 04CH37535), vol. 3. IEEE, 2004, pp. 1971-1974.

[2] A. B. Adipurnama, H. Wijanto, and Y. Wahyu, "Perancangan dan realisasi antena mimo $4 \times 4$ mikrostrip patch persegi panjang 5, 2 ghz untuk wifi 802.11 n," eProceedings of Engineering, vol. 3, no. 1, 2016.

[3] I. R. Utomo, D. Arseno, and Y. Wahyu, "Perancangan dan realisasi antena mimo 2x2 mikrostrip patch persegi panjang 5, 2 ghz untuk wifi $802.11 \mathrm{n}$ dengan catuan emc (electromagnetically coupled)," eProceedings of Engineering, vol. 5, no. 1, 2018.

[4] C. A. Balanis, Antenna theory: analysis and design. John wiley \& sons, 2016.

[5] K. Chang, V. Nair, and I. J. Bahl, $R F$ and microwave circuit and component design for wireless systems. John Wiley \& Sons, Inc., 2001.

[6] S. Vajha and S. Prasad, "Design and modeling of proximity coupled patch antenna," in 2000 IEEEAPS Conference on Antennas and Propagation for Wireless Communications (Cat. No. 00EX380). IEEE, 2000, pp. 43-46.

[7] S. Maci and G. B. Gentili, "Dual-frequency patch antennas," IEEE Antennas and propagation Magazine, vol. 39, no. 6, pp. 13-20, 1997. 